\title{
DATING OF CARBONATE SYSTEMS USING Pb-Pb ISOTOPE SYSTEM
}

\author{
BULAT GAREEV, GEORGII BATALIN AND ANDREY
}

CHUGAEV

Kazan Federal University

Presenting Author: bulat@gareev.net

On the basis of the laboratory of isotope geochemistry of the Institute of Geology and Oil and Gas Technologies of the Kazan Federal University, a unique method for direct dating of carbonate rocks based on the study of the $\mathrm{Pb}-\mathrm{Pb}$ isotope system has been developed and implemented. It includes a set of chemical procedures (selective dissolution of samples, ion exchange chromatography, etc.), which ensure the production of pure lead preparations from carbonate rocks at a minimum level of background contamination (less than $0.1 \mathrm{ng}$ ). The mass spectrometric part of the technique is based on the use of multicollector mass spectrometry with the ionization of matter in an inductively coupled plasma, which ensures high accuracy in measuring $\mathrm{Pb}$ isotopic ratios. Experimental work performed with reference solutions of $\mathrm{Pb}$, as well as international standards for $\mathrm{Pb}$ isotopic composition (SRM-981 and BCR-1) made it possible to determine the optimal operating modes of the NEPTUNE PLUS mass spectrometric complex equipped with a J-interface and the ARIDUS II desolvating system. It has been established that the technique provides correct and reproducible $\mathrm{Pb}-\mathrm{Pb}$ data. In this case, the achieved analytical error in measuring the isotopic ratios $206 \mathrm{~Pb} / 204 \mathrm{~Pb}, 207 \mathrm{~Pb} / 204 \mathrm{~Pb}$, and $208 \mathrm{~Pb} /$ $204 \mathrm{~Pb}$ does not exceed $0.03 \%( \pm 2 \mathrm{SD})$, which is an order of magnitude lower than in the TIMS method traditionally used in $\mathrm{Pb}$ isotopic analysis. The developed method was successfully tested in the study of Late Devonian carbonate rocks, for which a value of $357 \pm 45 \mathrm{Ma}$, which does not contradict geological data, was obtained. The work was supported by the Ministry of Science and High Education of the Russian Federation contract No. 14.Y26.31.0029 in the framework of the Resolution No.220 of the Government of the Russian Federation

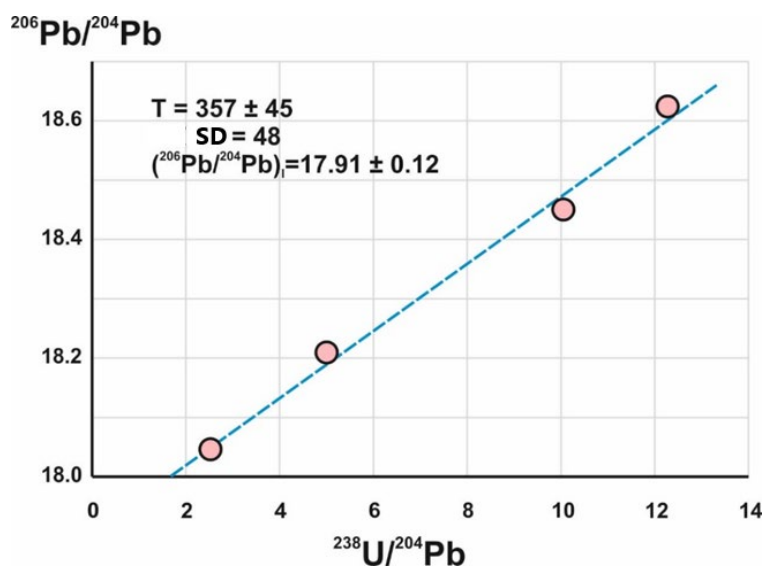

